\title{
Same-sex Marriage, Polygamy, and Disestablishment
}

The Progressive favors extending the legal institution of marriage so as to include same-sex unions along with heterosexual ones. The Traditionalist opposes such an extension, preferring to retain the legal institution of marriage in its present form. In this paper I argue that the Progressive ought to broaden her position, endorsing instead the Liberal case for extending the current institution so as to include polygamous unions ${ }^{1}$ as well. For any consideration favoring the Progressive position over the Traditionalist one is likewise a consideration favoring the Liberal position over the Progressive one. Progressives who accept this conclusion face a choice: they may affirm the Liberal stance favoring the legal recognition of other sorts of non-traditional family unions besides same-sex

\footnotetext{
${ }^{1}$ Two notes on terminology: (1) What is included: In popular discourse, polygamy is often conflated with polygyny, though that is not how the term is used here. I shall construe 'polygamy' broadly to include any union of three or more persons, of whatever gender(s). Thus, polygamy includes cases of polygyny (a man having more than one wife), polyandry (a wife having more than one husband), 'group marriage' (sometimes called polygynandry - the case where more than one man and more than one woman form a single family unit, all members of whom share parental responsibilities for any children that result), as well as various forms of unisex $n$-tuples (where $\mathrm{n}>2$ ) which do not (yet) have common names. (2) What is excluded: (i) The term bigamy is sometimes thought to denote the practice of having two wives, but all things considered is probably best reserved for the criminal act of secretly marrying one person while still legally married to another. Inasmuch as bigamous acts require deceit, they fall beyond the scope of the arguments offered here, which are intended to cover only cases of fully-consensual unions of three or more persons. (ii) The term polyamory does not, as yet, appear to have a settled meaning, but I shall use it to refer to the practice of conducting 'overlapping' romantic relationships. To illustrate: Chris may simultaneously conduct romantic relationships with both Kelly and Kim, whilst Kim simultaneously conducts a romantic relationship with Pat. If Chris, Kelly, Kim and Pat are all fully apprised of each other's existence and role, then all are engaged in the practice of polyamory. (Though perhaps to varying degrees: we may hold that, inasmuch as they conduct multiple romantic relationships simultaneously, Chris and Kim are more fully implicated in the practice of polyamory than are Kelly and Pat, who each maintain only one romantic partner.) Thus construed, the overlapping nature of polyamorous relationships creates difficulties for the attempt to broaden the current institution of civil marriage so as to accommodate polyamory; therefore, questions of the legal recognition of polyamorous 'marriages' (whatever such marriages might amount to) fall outside the scope of this paper. (It should be noted that this characterization of polyamory is a bit stipulative, as one frequently finds it used as an umbrella term encompassing, not only the 'overlapping' relationships I just described, but also all cases of polygamy. But the phenomenon of overlapping relationships which do not jointly constitute a single family unit - the phenomenon I have labeled 'polyamory' - represents an important category, which for our purposes must be isolated and excluded. Thus I claim the right to stipulate terminology in this fashion.)
} 
marriages, or they may affirm the Libertarian ${ }^{2}$ stance that favors instead the 'disestablishment' of marriage. $^{3}$

This paper proceeds in three sections. ${ }^{4}$ In the first, I sketch two important arguments widely advanced in favor of the Progressive position on same-sex marriage (henceforth 'SSM'), demonstrating in each case that such reasoning favors, not only the Progressive position, but also the Liberal one. In the second, I articulate and respond to an objection the Progressive might advance to the effect that - the arguments considered in Section 1 notwithstanding - there are strong countervailing reasons to restrict the institution of marriage to couples, rather than extending it to triples, or to any other $n$-tuples. In the third and final section, I offer an alternative position the Progressive might endorse, should she find herself uncomfortable embracing the full suite of Liberal recommendations. This is the Libertarian position that the state ought not be in the 'marriage business' in the first place, as the whole affair of recognizing and privileging only certain types of contractual union - and conferring an honorific title on said unions, with all its attendant legal privileges - is fraught with moral peril from the outset. For it is difficult for the state to undertake this venture and maintain any semblance of neutrality with respect to its citizens' competing and divergent conceptions of life's meaning and value. Recognizing this fact, the state's proper course of action is to quit (ideally, never to enter) the field entirely, devolving the thorny question as to which

\footnotetext{
2 As with the term 'polyamory', I claim the right to stipulate usage of Traditionalist, Progressive, Liberal, and Libertarian in this fashion, so as to facilitate ease of reference to each of the contending positions under consideration. While my usage is stipulative, it is of course not arbitrarily stipulative: the position denoted by each of these labels is consistent with the position one would expect to associate with persons who self-apply each of those labels more generally. Nevertheless, it is worth emphasizing that one might endorse, e.g., the Libertarian stance vis-à-vis disestablished marriage, without endorsing libertarian political thought more generally.

3 Of course, they may also reconsider the merits of Traditionalism. But such a reconsideration represents a radical enough departure from their prior Progressive proclivities that I need not consider its possibility in what follows.

${ }^{4}$ In what follows I will limit my discussion to the situation in the United States. Thus, discussion of the particulars of, e.g., federal vs. state marriage policy, the particular tax benefits and legal entitlements determined by public policy, etc. will reflect the U.S. case - but the substance of the argument should generalize to any (liberal) polity.
} 
unions are legitimately sanctifiable as 'marriages' to the private sphere - a question for churches, synagogues and mosques, not for courts and legislatures.

\section{Progressivism against Traditionalism}

There are, of course, a number of arguments that have been made, and might be made, in favor of the Progressive stance. We can get a handle on the diversity of Progressive arguments by first dividing the field into the categories of 'offensive' and 'defensive' arguments. 'Offensive' arguments 'go on the offensive' by offering affirmative considerations in favor of reforming the legal institution of marriage so as to include same-sex unions. 'Defensive' arguments, by contrast, arise in response to particular Traditionalist arguments against legalizing SSM - they seek to reject or undermine these 'offensive' Traditionalist arguments. While we cannot hope to consider the full range of Progressive arguments here, we can at least aspire to investigate a duly representative sampling. Thus, let us examine one example each of 'offensive' and 'defensive' Progressive argumentation.

Before proceeding with this investigation, though, it is worth pausing to note a curious fact. Why do we find so many defensive Progressive arguments in the literature - indeed, why do we find any at all? Given that the current status quo does not include same-sex marriage, is not the Progressive side the team that's 'playing offense'? Nevertheless, a considerable amount of Progressive argumentation does adopt a defensive posture. I suggest that this puzzling phenomenon arises due to a peculiar feature of the same-sex marriage issue. Namely, that - while in a somewhat narrow sense, the Traditionalist side represents the status quo - there is at the same time a 'wider' sense, in which it does not. For there is an intuitive sense in which the Traditionalist position represents a departure from the prevailing liberal norms that are generally operative in contemporary western 
democracies - the 'wider' status quo, if you will. And I suspect most Traditionalists sense this - they recognize that their position represents something of a departure from the liberal 'default', and thus stands in need of special justification. So Traditionalists are not content to adopt the posture of the incumbent, or the defendant in a courtroom trial, whose innocence is presumed until guilt is proven; they are not content to sit back and let the Progressives bear the full burden of proof. The Traditionalists realize that they must play quite a bit of 'offense' too, in order to motivate their preferred deviation from the liberal norms of, e.g., equal opportunity and equal treatment. This offensive activity, in the service of justifying the present limitation of marriage to heterosexual unions, has naturally prompted a Progressive response. Thus do we observe much argumentation of a 'defensive' character, from what would otherwise be the predominantly 'offensive' team.

Where ought the burden of proof to lie, then? We might think that we should organize our investigation so as to place the full argumentative burden on the Traditionalist, demanding that she give an account of her preferred departure from wider liberal norms. I have some sympathy with this position, since I share the rough intuition that current marriage policy represents an injustice. But as we shall see shortly (in section 1.1), things are not quite so simple: this rough intuition proves surprisingly difficult to formulate in any precise fashion. And in any event, it is the Progressives who are advocating a departure from the narrower status quo - and it is this narrower status quo that represents the relevant site of the argument. I thus conclude that the Progressive properly bears the burden of proof. Let us proceed, then, with our examination of two important Progressive arguments - beginning with an 'offensive' argument that I will call the 'Equal Rights Argument'.

\section{1 'Offensive' Progressivism: The Equal Rights Argument}


The intuition is simple: under current arrangements, heterosexual couples have the right to marry, whereas same-sex couples do not. As such, same-sex couples suffer an undue restriction on their personal liberty at the hands of state policy; they do not have equal access to the full complement of civil rights to which their heterosexual co-citizens have access.

This simple intuition proves difficult to formulate in any rigorous fashion, however. To appreciate this difficulty, begin by observing that it is couples who are said to be disadvantaged by said restricted liberty, and whose rights are infringed. But what can it mean to regard a couple as a bearer of rights? Typically, we regard individuals to be the bearers of rights (and duties). This is not to say that notions of collective rights (and duties) cannot be formulated and defended. The point is that it is a matter of some difficulty and controversy how (and when it is appropriate) to do so. If we wish to appeal to the simple intuition that current marriage law unduly deprives same-sex couples of their equal rights, we thereby set ourselves the difficult task of formulating and defending a notion of (nonindividually-borne) comples' rights, suitable to our purposes. It would thus seem advisable (should it turn out possible) to elaborate our simple equal-rights-respecting intuition in such a way that we do not thereby incur the duty to defend such a notion. ${ }^{5}$

Fortunately, such an elaboration is in the offing: for we can quite naturally cast the thought as one apropos individual rights: under current arrangements, heterosexual individuals enjoy the right to marry, whereas gay and lesbian individuals do not. Nonetheless - while it represents an

\footnotetext{
5 A note on the prospects for developing a notion of 'couples' rights', should readers think this route less beset with difficulty than I am suggesting: the law does recognize different sorts of persons. There are individuals, of course. But there are also corporations, which in many respects - some controversial - are treated as persons in U.S. federal law, as per a tradition of interpretation of the Fourteenth Amendment inaugurated in the 1886 Supreme Court case Santa Clara County vs. Southern Pacific Railroad Company (118 U.S. 394). So there are lots of areas, besides the formulation of a notion of a couples' right, where we can think through the ethical dimensions and implications of our current practice of conferring legal recognition on such 'quasi-persons'. The Supreme Court's recent ruling in Citizens United vs. Federal Elections Commission (558 U.S. (2010)), for instance, raises questions about the extent to which corporations' 'speech' should be protected under the First Amendment.
} 
improvement - this formulation will not suffice either. For consider the simple fact that homosexual individuals, no less than heterosexual ones, enjoy the right to marry. So long as he or she is willing to marry a person of the opposite sex, no gay or lesbian person will experience an infringement of his or her right to marry, under current arrangements.

We should furthermore note that - as thus far construed - heterosexual individuals who remain single have just as strong a claim to being the victims of discrimination, as do homosexual individuals. Whatever rights and privileges are denied gays and lesbians in this regard are likewise unavailable to single persons of any sexual orientation. After all, we might say, no one is legally prohibited from entering into a (heterosexual) marriage; it can't be the state's fault, or responsibility, if - for whatever reason - some individuals choose not to enter these relationships. The state, we might think, ought to be indifferent as to persons' various reasons for not entering into marriage whether these reasons owe to a lifestyle choice, to bad romantic luck, to the maintenance of extremely high standards for mates ... or to sexual orientation.

So perhaps we need to say that, unlike their heterosexual fellow citizens, homosexuals do not enjoy the right to marry the persons they love. ${ }^{6}$ But positing a 'right-to-marry-the-person-you-love' is similarly fraught with difficulty. For that we do not enjoy a guarantee to marry the person of our desires is a fact likewise lamented by innumerable unrequited heterosexual lovers, who are unlikely to recognize the plight of homosexuals as unique in this regard.

But perhaps we can hone in on the proper formulation even more closely by noting that - unlike their unlucky-in-love heterosexual counterparts - homosexuals are deprived of their right even to

${ }^{6}$ The 'right-to-marry-the-person-you-love' formulation is adopted by, for example, Jonathan Rauch: see his "Marrying Somebody," in Same-Sex Marriage: Pro \& Con, Andrew Sullivan, ed. (New York: Vintage Books, 2004), p. 284. 
marry those persons who are willing to marry them. (The question whether, in giving this formulation, we have for all intents and purposes circled back round to a formulation that invokes something like a couple's right is one I will note, but not here entertain.) In this regard, the (individualistically-construed) right in question looks like a liberty to enter into a (certain kind of) mutually-advantageous contractual union - we might speak of a right to 'full freedom of contract with respect to life-partnerships.'

Is this the most promising formulation of the simple intuition with which we began? Not quite: even here, difficulties lurk. For by casting the point in terms of a right-to-enter-into-mutuallyadvantageous-contractual-unions, as we have just done, we highlight the fact that this right likewise does not appear to be wholly and utterly infringed in the case of gay and lesbian individuals. Many of the legal rights and privileges automatically conferred upon persons when they become married are similarly available to persons in same-sex unions. Same-sex couples have equal access to the legal machinery whereby they can draw up private contracts conferring upon their partners many of the same rights of, e.g., inheritance, power of attorney, joint ownership of assets, visitation rights, and so forth. ${ }^{7}$ Since they have an equal right to enter into contractual relations with their partners, same-sex couples seemingly enjoy many of the same legal liberties, rights and privileges as married couples. Furthermore, we should note that in some jurisdictions, these liberties, rights and privileges are often available with the same convenience with which heterosexual couples find they can access these privileges: states that recognize same-sex civil unions offer same-sex couples a pre-packaged way of conveniently securing essentially the same legal privileges that married couples enjoy.

\footnotetext{
${ }^{7}$ This last right - visitation rights in, say, a hospital - raises an important point that I cannot fully discuss here: the fact that many of the rights and privileges to which same-sex couples lack access are not legal rights and privileges, but rather privileges and prerogatives conferred by private institutions.
} 
However, many Progressive activists are not content with this institution of 'ersatz marriage', made available either through the machinery of civil unions, or through more complicated 'DIY' legal contracting. They may cite either of (at least) two sources of this dissatisfaction. The first is the fact that even civil unions do not confer the full suite of rights and privileges that married couples enjoy. This is because federal law does not recognize civil unions (the 1996 'Defense of Marriage Act' stipulates that for federal purposes, a marriage shall be "the legal union between one man and one woman as husband and wife"), and so federally-conferred benefits are still not available to couples who enter into civil unions. These benefits include federal tax benefits, cross-state recognition of their marriages, immigration sponsorship privileges, and so forth. ${ }^{8}$

A second source of Progressive dissatisfaction with the institution of 'ersatz marriage' currently available to same-sex couples is the unequal public recognition afforded by civil unions (and other forms of 'simulated' marriage), compared to full-fledged marriages. For many, it is the fact that, when it certifies them as being 'married', the state confers an honorific, a kind of legal status, onto heterosexual couples - a kind of honorific or status not available to same-sex couples. Dissatisfaction with currently-available forms of ersatz marriage reveals that for many Progressives, unequal access to this honorific, or public and legal status, is a main source of discontent. The title of 'marriage' itself is where much of the action is.

So perhaps we have at last isolated the fundamental source of dissatisfaction, and given strongest formulation to our initial intuition respecting unequal rights: insofar as the state confers the

${ }^{8}$ For a brief survey of such benefits, see http://lesbianlife.about.com/cs/wedding/a/unionvmarriage.htm. Famously, in 1997 - in response to queries raised by the previous year's passage of the Federal 'Defense of Marriage Act' - the G.A.O. (now the 'Government Accountability Office'; then the 'General Accounting Office') conducted an audit in which it identified 1,049 federal benefits available to married couples. An updated audit conducted in 2004 "identified a total of 1,138 federal statutory provisions classified to the United States Code in which marital status is a factor in determining or receiving benefits, rights, and privileges." This audit is available on the web at http://www.gao.gov/new.items/d04353r.pdf 
honorific of 'married' upon heterosexual individuals who wish to secure public recognition and certification of their relationships (provided their relationship partners wish likewise) - yet the state withholds this honorific from similarly-situated homosexual individuals - the individuals who comprise same-sex couples are deprived of a right available to many of their fellow citizens. They have unequal access, unequal liberty.

To recap: we begin with the simple intuition that same-sex couples suffer an undue restriction on their personal liberty at the hands of state policy, inasmuch as they do not have equal access to the full complement of civil rights to which heterosexual couples have access. We must refine this intuition, though, so as to accommodate the difficulties posed by a series of successive challenges. The first challenge is that the rights in question are more plausibly construed as individual rights, rather than as "couples' rights." The second challenge is that technically, gay and lesbian individuals do have equal access to the same individual rights, liberties and privileges as heterosexuals, inasmuch as they are not legally prohibited from marrying. The solution to this challenge was to construe the right in question as the right to marry the person one loves. It was immediately noted, however, that not even heterosexuals enjoy anything like a right-to-marry-the-person-you-love. (For what if that person doesn't want to marry you?) Formulating the matter with an appeal to the fact that heterosexuals, unlike homosexuals, enjoy the right to enter into a mutually desired contractual arrangement for life-partnership, we found we'd gone a considerable way towards adequately capturing the intuitive injustice in current marriage policy. But many of the legal benefits which accrue to married partners pursuant to their entering a marriage contract are, we noted, likewise available to same-sex partners through various other forms of legal machinery - whether through civil unions, or more 'DIY' faux-marriage contracts. Thus, we concluded, Progressive opposition to current marriage policy results from either of two things: from the deficit in legal rights and 
privileges that still remains, even between civil unions and marriages (most of this deficit resulting from the federal government's non-recognition of same-sex marriages), or from the fact that even if (pace current federal marriage policy) ersatz marriage contracts were able to confer the exact same set of rights as genuine marriage contracts, these unions would not be accompanied by the same degree of public recognition and endorsement. Of the two remaining sources of Progressive dissatisfaction, we cited the latter as likely the stronger. ${ }^{9}$ Thus, we finally isolated the crucial, infringed, unequally-distributed right as the right to enter into a mutually desired contractual arrangement that bears a certain status of public and legal recognition - that of the title of 'marriage.'

At its root, the difficulty we have just experienced in identifying the precise right alleged to be abridged or violated by current marriage policy (at least in jurisdictions not recognizing same-sex marriages) likely stems from the failure to adequately distinguish rights from powers, in Wesley Hohfeld's sense of the terms. ${ }^{10}$ According to Hohfeld's classic exposition, ${ }^{11}$ powers are 'secondary rules' specifying how persons may introduce, alter, or rescind the 'primary rules ${ }^{12}$ governing the actions they and others are prohibited, permitted, or obligated to perform. A power, thus, is a rule specifying how a person may create or alter his or her rights (and liberties) - it is not itself a right (or a liberty). The legal 'right (or liberty) to marry' is therefore actually a power. Specifically, it is the power to effect certain legal rights, privileges and immunities with respect to another person - e.g.,

\footnotetext{
${ }_{9}$ Ralph Wedgwood concurs, identifying this complaint as a central component of the 'fundamental argument for samesex marriage': "there is a basic inequality in the fact that same-sex couples, unlike opposite-sex couples, are denied the marital status itself; and we must also argue that this marital status is an important matter, not a mere piece of legal flummery." (Emphasis in the original.) See Wedgwood, Ralph: "The Fundamental Argument for Same-Sex Marriage," The Journal of Political Philosophy 7(3) [1999]: 225-242, p. 227.

${ }^{10} \mathrm{I}$ am indebted to Christopher Morris for bringing this issue to my attention.

${ }^{11}$ Fundamental Legal Conceptions as Applied in Judicial Reasoning, Yale University Press (1946). An article of the same title first appeared in 26 Yale Law Journal 710 (1917).

12 The terms 'primary rule' and 'secondary rule' are taken from Hart, H. L. A. [1961]. The Concept of Law. Oxford: Oxford University Press.
} 
the claim-right to survivor benefits in the event of a partner's death, the privilege of spousal sponsorship for immigration and naturalization purposes, and the immunity from being required to testify against one's spouse. ${ }^{13}$

Once we recognize that the right to marry is actually a Hohfeldian power, we can more precisely identify the injustice inherent in legal jurisdictions that do not recognize same-sex marriages - the same injustice that often gives rise to the (as we now see) confused claim that same-sex couples do not have the 'right to marry': it is that the legal frameworks in such jurisdictions limit citizens' powers in certain arbitrary ways. The power to create the cluster of legal rights, privileges and immunities typically associated with marriages is available only to oppositely-sexed pairs of individuals who jointly wish to create a legally-recognized contractual life-partnership. Advocates of same-sex marriage can rightly point out that the foregoing restriction is arbitrary and unjust: why should these powers not be available to same-sexed pairs of individuals who likewise wish to create legallyrecognized life-partnerships?

Of course, once we recognize this, we are compelled to recognize that the current restriction of marriage-making Hohfeldian powers to oppositely-sexed pairs is every bit as arbitrary or unjust as the current restriction of such powers to oppositely-sexed pairs. The Progressive cannot afford to be selective in her complaint about the arbitrary and unjust restrictions on marriage-making powers embodied in such legal frameworks. If she is to object to the current restrictions which disadvantage same-sex two-person unions, she must also take on board the Liberal's objection to the current restrictions which disadvantage polygamous unions.

\footnotetext{
13 The foregoing discussion of the Hohfeldian framework for understandings rights and powers is much indebted to Leif Weinar's exposition in the Stanford Encyclopedia of Philosophy: http://plato.stanford.edu/entries/rights/, accessed September 24, 2010.
} 
In sum, the so-called 'Equal Rights' argument works equally well as an argument for extending the current institution of marriage to polygamous unions as well as to same-sex unions. For we have avoided the difficult task of formulating and defending a notion of a couples' right, preferring instead to cash out our intuition in terms of individual rights (and powers). Thus one cannot object that the argument does not extend to polygamous unions on grounds that it's an argument specifically about the rights of couples. If homosexual individuals should have the power to enter into legally-certified unions currently restricted to heterosexual individuals, why should not polygamously-inclined individuals enjoy the same power? If the crucial 'right' in question is to be construed (as I think we've seen it must be) as the right of equal access to the legal machinery whereby the state confers an honorific status upon a mutually-consented-to contractual union, what grounds can there be for restrictions on the number of parties to the union in question? And clarifying the case by recognizing that the abridgement in question is not actually one of rights, but rather of powers, only reinforces the intuition that what's arbitrary and unjust about current marriage regimes applies equally well to its restrictions regarding polygamous $n$-tuples as to its restrictions regarding same-sex couples. Articulating these points in the language of the federal Defense of Marriage Act, we might say: if one can legitimately object to the federal definition of marriage as the "legal union of one man and one woman", why can't one just as legitimately object to the definition of marriage as the "legal union of one man and one woman"? If the Equal Rights Argument establishes the Progressive position vis-à-vis SSM, does it not likewise establish the Liberal position? ${ }^{14}$

\footnotetext{
14 We should pause to note that, at this point in the dialectic, the Progressive may be tempted to object that the whole discussion in 1.1 crucially erred by casting the issue in terms of positive rights. According to this objection, the infringed right in question is not, as I'm assuming, a positive right (or a power) to effect certain legal status. Rather, it's a right to be free from certain arbitrary interference - viz., the right to be free from undue interference to seek and procure civil marriage licenses, say. The rights-violation embedded in current marriage policy, then, is actually a violation of a negative right. I am skeptical that such a case can be made: If marrying were (what we might term) a 'natural' action, it might make sense to think of it as being subject to the sort of interference that would constitute a negative rights violation. But marriage is of course not a 'natural' action in the relevant sense; it is a 'conventional' (or, perhaps, an 'institutional') action. Current
} 


\section{2 'Defensive' Progressivism: The BYCBS Argument}

Before we can fully appreciate 'defensive' Progressive argumentation, we must have a sense of the 'offensive' Traditionalist arguments to which it constitutes a response. Therefore, let us first briefly examine some important Traditionalist arguments.

\subsection{1 'Offensive Traditionalism'}

In what follows, I do not presume to have identified every argument made in favor of retaining the legal institution of marriage in its present form, nor even to have identified all the most important ones. Neither do I necessarily take myself to be offering the strongest possible formulations of the Traditionalist arguments I do cite. My purpose is only to sketch the Traditionalist arguments that have given rise to the important and compelling Progressive responses of which I am aware. So, for instance, I do not discuss the argument that grounds the prohibition of same-sex marriage in the claim that gay and lesbian sex is putatively unnatural, and thus immoral. Nor do I consider the sort of brute appeal to 'tradition' which cites the fact that few (if any) known societies have included same-sex unions within the purview of their customary marriage arrangements. ${ }^{15}$ I do not consider these arguments out of any prejudice against them, necessarily, but for the simple reason that they have not given rise to any particularly interesting Progressive counter-arguments. And they have not given rise to any particularly interesting Progressive counter-arguments, quite honestly, because they

marriage law may embody certain arbitrary restrictions on individuals' powers to associate with other individuals to perform certain 'conventional' or 'institutional' actions - but it does not seem apt to say that it embodies a violation of negative rights. Irrespective of the merits of framing the issue in these terms, however, it should serve to dispense with this line of argument by pointing out the parity claim holds equally well for this argument: if the individuals who comprise (would-be) same-sex marriages can legitimately claim that they're subjected to a negative rights violation, then the individuals who comprise (would-be) polygamous marriages can just as plausibly make this same claim. The 'negative rights' interpretation of the Equal Rights Argument fares no better, as a way of securing Progressivism without Liberalism, than does the interpretation explored in the main text.

15 Though I do consider a close cousin of this view - the 'Hayekian Argument' - with which the brute appeal to Tradition might be confused. The 'Child-Rearing Argument', also considered below, might be regarded as a slightlymore-distant cousin of the brute appeal to Tradition. 
are not very strong arguments in the first place. To counter the former argument, it suffices to remind the reader of the fact/value distinction. To counter the latter, it suffices to point out that such brute appeal can likewise justify, e.g., anti-miscegenation laws - and, for that matter, polygamous marriage. ${ }^{16}$ Thus, while these arguments might have some currency in the wider culture, they are not typically encountered in the philosophical literature. Philosophical defenses of Traditionalism, rather, tend to assume either of two forms: there is a consequentialist argument that (following Jonathan Rauch ${ }^{17}$ ) I will call the 'Hayekian Argument', and there is a form of 'essentialist' argumentation that I will call the 'Child-Rearing Argument'. Let us examine each in turn.

Progressive advocate Jonathan Rauch reckons the Hayekian Argument to represent the strongest defense of Traditionalism; I will quote at length his explanation of it: ${ }^{18}$

In a market system, the prices generated by impersonal forces may not make sense from any one person's point of view, but they encode far more information than even the cleverest person could ever gather. In a similar fashion, human societies evolve rich and complicated webs of non-legal rules in the forms of customs, traditions, and institutions. Like prices, the customs generated by societies may often seem irrational or arbitrary. But the very fact that they are the customs that have evolved implies that there is a kind of practical logic embedded in them that may not

\footnotetext{
${ }^{16}$ See Garrett, Jeremy R. ("History, Tradition, and the Normative Foundations of Civil Marriage." The Monist $91(3$ \& 4) [2008]: 446-474) pp. 447-52, for a fuller discussion of the range of objections besetting this "bald appeal to tradition." For a helpful overview of the sources of support for polygamy found within the Judeo-Christian tradition, specifically, see Calhoun, Cheshire: "Who's Afraid of Polygamous Marriage? Lessons for Same-Sex Marriage Advocacy from the History of Polygamy." San Diego Law Review 42 [2005]: 1023 - 1042. See especially pp. 1027-30.

${ }^{17}$ See Rauch, Jonathan: "Who Needs Marriage?" in Beyond Queer: Challenges for Gay Left Orthodoxy, ed. Bruce Bawer, Free Press 1996. Reprinted in White, James E., ed. Contemporary Moral Problems, 9E. Thomson, 2009: pp. 257-66.

18 Though I focus on Rauch's articulation of this position, readers interested in a more detailed examination are directed to Garrett [op. cit., 453-8], who helpfully distinguishes (among other things) between 'Burkean' and 'Hayekian' versions of the argument. He terms these the arguments from 'Accumulated Wisdom' and 'Evolutionary Fitness', respectively.
} 
be apparent from even a sophisticated analysis. And the web of custom cannot be torn apart and reordered at will, because once its internal logic is violated, it falls apart. $^{19}$

Rauch cites Hayek's The Fatal Conceit as the best-developed example of this general line of thought (though Hayek's discussion is general, and does not focus on marriage in particular). Furthermore, Rauch allows that there is ample evidence for the claim that toying with the traditional form of the institution of marriage does have disruptive effects:

Age-old stigmas on illegitimacy and out-of-wedlock pregnancy were crude and unfair to women and children. On the male side, shotgun marriages were, in an informal way, coercive and intrusive. But when modern societies began playing around with the age-old stigmas on illegitimacy and divorce and all the rest, whole portions of the social structure just caved in. ${ }^{20}$

The Child-Rearing Argument, meanwhile, is perhaps the most common case for Traditionalism, and Maggie Gallagher perhaps its best-known proponent. ${ }^{21}$ According to this argument, because marriage is essentially about the bearing and raising of children, and because same-sex couples, by their nature, cannot bear their own children, there is no particular reason why they should be included in the institution of marriage. Like many Traditionalists, Gallagher locates the evidence for her central essentialist claim in historical precedent. She contends that - notwithstanding the

\footnotetext{
${ }^{19}$ Rauch [op. cit., 259].

${ }^{20}$ Ibid.

${ }^{21}$ It is also worth noting that, in addition to its presence in the philosophical literature, the Child-Rearing Argument has been appealed to by virtually every United States court that has upheld the legitimacy of SSM prohibitions. I am indebted to an anonymous reviewer from Social Theory and Practice for bringing this point to my attention.
} 
relatively recent (in historical terms) tendency to understand the marital covenant as representing the public certification, recognition and registration of certain bonds of intimacy - there is a longerstanding and better-establish custom which locates its primary purpose in the task of raising children. "Marriage is the fundamental, cross-cultural institution for bridging the male-female divide so that children have loving, committed mothers and fathers," she writes. It is necessary because "[m]ost men and women are powerfully drawn to perform a sexual act that can and does generate life. Marriage is our attempt to reconcile and harmonize the erotic, social, sexual, and financial needs of men and women with the needs of their partner and their children."22 The fact that, at its core, the purpose of marriage is to create and nurture children, together with the fact that state and society have a fundamental stake in the successful bearing and raising of future citizens, provides the rationale for reserving the institution for heterosexual couples.

Thus far, the Hayekian and Child-Rearing arguments. There are, as we noted, other arguments advanced in support of the Traditionalist cause. But coming to a brief understanding of these two arguments is necessary for understanding an important defensive Progressive argument to which they give rise. So let us now turn to this Progressive response.

\subsection{The BYCBS Argument}

The Progressive typically offers the 'But You Can't Be Serious?' argument (henceforth 'BYCBS') in response to such consequentialist and essentialist Traditionalist appeals. The argument's name derives - not from any incredulity that the sincere avowal of such Traditionalist positions might be thought to provoke - but rather from an ellipsis on the full articulation of the argument. This full articulation runs as follows: "You can't really be serious that $G$ is grounds for your opposition to $X$.

${ }^{22}$ Gallagher, Maggie: "What Marriage is For." The Weekly Standard August 4-11, 2003. Reprinted in White, James E., ed. Contemporary Moral Problems, 9E. Thomson, 2009: pp. 266-70. pp. 267-8. 
For if you were serious, you would recognize that $G$ is also grounds for a commitment to some activity or position $Y$. Yet the fact that you show no commitment to $Y$ reveals that you don't truly regard $G$ as the ground for your opposition to $X$. Instead, you're merely citing $G$ as your ground, because it's more palatable, or plausible, or publicly acceptable to cite $G$ as your ground, than it is to cite your true grounds."

Jonathan Rauch is one Progressive who offers this response. Rauch begins his BYCBS response to the Hayekian Argument by pointing out that any effects accruing from the legalization of SSM will pale in comparison - vis-à-vis their effects on the broader societal commitment to the institution of marriage - to those of other policies already in place, such as the recent liberalization of divorce laws. The advent of 'no-fault' divorce provisions in the 1970's, Rauch surmises, did far more to undermine the traditional institution of marriage and effect widespread social upheaval and disruption, than the legalization of SSM could ever do. At very least, Rauch concludes, Traditionalists can only conduct a good-faith campaign against legalizing SSM to the extent that it is one component in an overall larger campaign dedicated to preventing and reversing policy changes which they perceive as destructive or undermining of the traditional institution of marriage. In such a larger campaign, the crusade against SSM would be significantly overshadowed by efforts to reform and restrict divorce laws, restrict the availability of 'Vegas-style' weddings to impaired persons acting against their better (more sober) judgment ${ }^{23}$, and so forth. A good-faith comprehensive Traditionalist campaign to strengthen, preserve and protect the traditional institution of marriage would devote far greater energy and resources to these other causes, than to the opposition of SSM. The fact that so few Traditionalists do regard their opposition to SSM as a second or third priority in an overall effort to defend traditional marriage from its assault on all

\footnotetext{
${ }^{23}$ Perhaps by requiring a waiting period before one is able to obtain a marriage license?
} 
flanks, reveals that - whatever they may avow publicly - most Traditionalists are not after all concerned primarily with preserving the inherited features of marriage, so much as thwarting the interests of gays and lesbians.

Rauch's argument fits the BYCBS template sketched above, for he can be seen as delivering a version of the argument that substitutes 'defense of the traditional institution of marriage' for $G$, 'expansion of the institution of civil marriage to include same-sex unions' for $X$, and 'mobilization and advocacy to reverse current policies such as no-fault divorce and the easy availability of Vegasstyle weddings, with a level of urgency far surpassing that currently devoted to the opposition of SSM' for Y. But the BYCBS is also an apt retort to the Child-Rearing Argument. Simply fill in 'appeal to the essential function of marriage' for $G$, 'expansion of the institution of civil marriage to include same-sex unions' for $X$, and 'restricting marriage to only fertile couples' for $Y$. As Rauch discusses at length ${ }^{24}$, the Child-Rearing argument likewise provides a rationale for denying marriage to non-child-bearing heterosexual couples - whether their infertility be due to choice or to circumstance. Consistency would seem to demand that Traditionalists who defend their position with reference to the central child-rearing function of marriage should likewise advocate for, e.g., fertility tests for young couples applying for marriage licenses (perhaps along with a polygraph-aided profession of reproductive intentions?), and the denial of marriage licenses to older couples who have exceeded their child-bearing years. The fact that so few (if any) Traditionalists do lobby for these changes again reveals that - whatever they may avow publicly - these Traditionalists are not after all primarily motivated by a recognition of marriage's 'essential' features, so much as thwarting the interests of same-sex couples. Speaking of such campaigners, Rauch concludes, "In truth, their real posture has nothing at all to do with children, or even with the 'anatomical possibility' of

${ }^{24}$ Rauch [op. cit., 260-2] 
children. It is merely anti-gay. All it really says is this: the defining purpose of marriage is to exclude homosexuals." 25

As with its 'offensive' cousin, however, it is difficult to see why the BYCBS argument isn't properly seen as yielding a Liberal conclusion, rather than (merely) a Progressive one. For the 'But You Can't Be Serious?' objection can be turned back on its head, and deployed against the Progressive, in favor of the Liberal, revealing that many Progressives can't be serious about their advocacy for same-sex marriage on whatever grounds they claim. Else, if they were, they would also advocate for legalizing polygamous unions. Consider first the 'offensive' Progressive argument discussed in section 1.1. For the sorts of reasons we briefly considered at the end of that section, it is difficult to regard someone as making a good-faith appeal to the Equal Rights Argument, unless she likewise deploys it in the service of the Liberal cause. Invocation of the Equal Rights Argument in support of Progressivism, by someone who has duly considered (and yet rejected) the analogous equality-based argument for Liberalism, is apt to strike us as only so much special pleading, proceeding under the cover of admirable liberal notions such as 'equal opportunity' or 'equal liberty.' Furthermore, this result seems to be perfectly general. Consider, for example, another possible strategy of offensive Progressive argumentation, which we did not examine in Section 1.1: an appeal to consequentialist reasoning. Plausibly enough, invocation of a consequentialist argument in favor of Progressivism, by someone who has duly considered (and yet rejected) the analogous consequentialist argument for Liberalism, will merely invite the BYCBS retort. We would be tempted to regard such a Progressive

25 Rauch [op. cit., 262]. For other examples of this argument, see Macedo, Stephen. "Homosexuality and the Conservative Mind." Georgetown Law Journal 84 [1995]: 261-300; and Nussbaum, Martha. Liberty of Conscience: In Defense of America's Tradition of Religious Equality. New York: Basic Books, 2008: 344ff. Nussbaum's language at p. 345 also nicely captures the spirit of the BYCBS argument: "The failure to suggest such limits for heterosexual marriage [viz., to childbearing couples] suggests that the people who proffer the marriage-for-procreation argument don't really mean what they are saying, that the restriction on same-sex marriage is not supported, in actuality, by this plausible-seeming public argument but, rather, by fear that the heterosexual institutions will somehow be defiled ... the opponent of same-sex marriage, if sincerely committed to a consistent ethical principle, must conclude that we should drastically limit access to heterosexual marriage." 
as desirous of special state-conferred recognition or status for members of her preferred group though not for members of a rival, similarly-situated but non-preferred group - and then seeking cover for her special-interest lobbying under dubious consequentialist appeals.

Thus does an important 'defensive' Progressive argument, like its 'offensive' cousin, seemingly yield a Liberal conclusion. ${ }^{26}$ It's worth noting that this is actually a quite striking result. For it may have come as little surprise to readers that the Progressive's offensive arguments actually serve to support Liberal conclusions. But I take it that the results of section $\mathbf{1 . 2 2}$ were not as easily foreseen. It is I think rather surprising to learn that the moves the Progressive must make so as to counter Traditionalist arguments likewise commit her to Liberal conclusions. Perhaps the pressure on the Progressive to convert to Liberalism is even stronger than we might have anticipated.

\section{Progressivism against Liberalism}

So here we have seen two important arguments for Progressivism. I do not claim that the Equal Rights and BYCBS arguments exhaust the field, but I do believe they constitute a duly representative range of possible Progressive positions. From our brief discussion of the Liberal implications of these important Progressive arguments, we might hazard the conclusion that Progressivism actually collapses into Liberalism.

\footnotetext{
${ }^{26}$ Some readers are likely to object that the BYCBS argument, rather than being a reductio, is in fact nothing more than an ad hominem, and thus invalid. While I believe there may be grounds for resisting this allegation, I am not disposed to develop them. This is because I am indifferent to the merits of the BYCBS as such. Rather, I only wish to defend a parity thesis with respect to the BYCBS - vi\%, that whatever strength it has as a Progressive argument against the Traditionalist, it is at least as strong when deployed by the Liberal against the Progressive. And if indeed it turns out that the BYCBS isn't a very good Progressive argument, then that's fine with me. I am indebted to Terrence Watson for helping me to appreciate this point.
} 
Of course, this suggestion is not unfamiliar - it is often offered by the Traditionalist as part of her brief against the Progressive case for SSM. The Traditionalist's allegation is that the logic of the Progressive position compels us to move beyond simply making the case for SSM, to considering the merits of other sorts of unions besides. ${ }^{27}$ Progressives have typically resisted this allegation. They have sought to assuage their opponents by articulating reasons why we need not fear the Slippery Slope - principled reasons why the Progressive cause would rest with same-sex unions; reasons why polygamous unions do not deserve the same recognitions that same-sex (and heterosexual) unions do. ${ }^{28}$

In my opinion, this resistance is ill-advised. Progressives ought instead to embrace this charge, proclaiming it to be a feature rather than a bug. Few Progressives do, however. ${ }^{29}$ There are several reasons why this might be the case. First, many Progressives simply may not (yet) appreciate the full implications of their arguments in favor of same-sex marriage. Further, while some Progressives may appreciate the force of the Traditionalist's 'Progressivism leads to Liberalism' allegation, for obvious pragmatic and political reasons they wish to remain silent on this point, rather than to call attention to one more explosive feature of an already-controversial topic. Finally, yet other Progressives may feel the force of the preceding considerations, yet nevertheless maintain an intuitive opposition to the legal recognition of polygamous unions. Finding this intuitive opposition (or revulsion) at odds with their theoretical stance, vis-à-vis the Progressive arguments just surveyed,

${ }^{27}$ It is true, of course, that many Traditionalists have gone overboard with this argument, alleging that the 'Slippery Slope' the Progressives are urging us to venture onto terminates only with legal recognition of child marriages and bestial unions. It suffices to dispense with this line of reasoning to point out that quite a firm foothold can be reached before we ever arrive at such ground - children and animals cannot properly consent to the sorts of unions these Traditionalists fear, whereas presumably the adults party to polygamous unions can.

28 See, e.g., Wedgwood [op. cit., 242] and Corvino, John: “Homosexuality and the PIB Argument." Ethics 115 [2005]: 501534, though the latter argument focuses on the moral status of homosexual, polygamous, bestial, and incestuous activities in their own rights, not on marriage in particular.

${ }^{29}$ But see Calhoun [op. cit.] and Mahoney, Jon: "Liberalism and the Polygamy Question," Social Philosophy Today 23 [2008]: 161-174. 
they seek to identify or to articulate countervailing reasons that might serve to resist the seemingly inexorable Progressive slide into Liberalism. Some of the countervailing reasons these Progressives appeal to might simply be rationalizations. But there is at least one such consideration that has wide currency and surface plausibility, and which therefore merits our attention: the observation that polygamous societies generally, and polygamous unions particularly, are frequently characterized by a host of unsavory practices such as sexism, exploitation and even rape. Call this the 'Objection from Unsavoriness'. The inegalitarian, illiberal nature of polygamous unions - a feature that is absent from the sorts of same-sex unions favored by Progressives - provides grounds for resisting the slide into Liberalism. It gives the reticent Progressive a principled reason to affirm support for same-sex marriage, while simultaneously withholding support from the movement to extend the legal institution to include polygamous unions. Unfortunately for this Progressive, though, this Liberalresisting argument is uncompelling.

Before we examine the Objection from Unsavoriness, we should first note the unavailability of a wide range of natural considerations to which our reticent Progressive might initially wish to appeal. She cannot appeal to the traditional notion of marriage as an institution regulating couples, and insist that triples have no place in this club. She cannot avail herself of the Hayekian insight that radical revision to long-established, culturally-evolved institutions effects social disruption and displacement. Nor can she invoke the Child-Rearing Argument, absent a compelling reason to think that children raised in polygamous homes are more at risk for various negative outcomes than are children raised by two parents of the same sex. ${ }^{30}$ The Progressive cannot make any of these appeals, of course, because in each case there is an analogous argument to be made in favor of the

\footnotetext{
30 There is relatively little empirical evidence regarding the child-welfare effects of polygamous parenting. For an overview of this small body of literature, see section II of Brooks, Thom: "The Problem with Polygamy" (January 22, 2009). Available at SSRN: http://ssrn.com/abstract=1331492 Forthcoming in Philosophical Topics.
} 
Traditionalist stance over the Progressive one. These analogous arguments are at least as strong - and plausibly, stronger - when made in favor of the Traditionalist position. By parity of reasoning, then, the Progressive cannot invoke these considerations without legitimating the parallel Traditionalist arguments that appeal to, e.g., the traditional notion of marriage as a heterosexual two-person union. The Objection from Unsavoriness, on the other hand, is somewhat immune from the worry that it actually supports Traditionalism by parity of reasoning - for while there is an analogous Traditionalist version of this Objection, it is a much weaker version than the Progressive's brief against the Liberal. ${ }^{31}$

Returning our attention to the Objection from Unsavoriness, we must concede at the outset that there is considerable empirical merit to the claim that many observed instances of polygamous practice - both past and present - do involve patterns of patriarchal oppression and exploitation. Included among these are patterns of pervasive rape, child marriage, and forced dependency. This strong correlation provides inductive grounds for 'polygamy pessimism': the worry that future polygamous practices will be similarly pervaded with exploitation. Liberalism - the position that is seen to gladly countenance such future patterns of exploitation, and even to legitimate them by endowing them with legal recognition and status - is therefore rejected in favor of Progressivism the position that pursues a strategy of containment with respect to these exploitive tendencies.

But we may grant the validity of the empirical observations that underwrite the Objection from Unsavoriness $^{32}$, without admitting that the Objection proves fatal to the Liberal cause. For we can

\footnotetext{
31 Though, as we note in our discussion just below, the Traditionalist Objection from Unsavoriness arguably may have been more compelling a generation or so ago.

32 At this point, we should address a potential terminological objection: the Progressive may oppose usage of the phrase 'Objection from Unsavoriness' to refer to her argument here. Such terminology suggests that the Progressive merely finds polygamy to be distasteful or disgusting, when in fact she is opposed to the genuine harms that often result from polygamous unions, as detailed above. Notwithstanding the reasonableness of this objection, I prefer to retain this label
} 
observe that the connection between polygamy and these unsavory practices, while real, may be merely contingent. And we might further hypothesize that, were the institution of polygamous union to be normalized (say, by according it legal recognition and protection), this contingent connection might be severed, and the practice of polygamy would shed many of its unsavory associations. We might ask, that is, the 'Chicken or the Egg?' question regarding polygamy's unsavory associations. Playing the proverbial roles of 'chicken' and 'egg' are the marginalization of polygamous societies (such as the Fundamentalist Church of Jesus Christ of Latter Day Saints (FLDS)), on the one hand, and the aforementioned illiberal, inegalitarian character of such societies, on the other. Granted, this relationship is symbiotic, and the marginalization and unsavoriness are likely mutually reinforcing. But we can still ask which of these two 'causal arrows' predominates. Is the 'fringe' status of polygamous groups ${ }^{33}$ the result of their pervasive unsavoriness in matters of family organization - an unsavoriness perhaps inherent in the very nature of polygamous unions? Or is it rather the case that "the illegality and attendant marginalization of polygamy" is what pushes it out onto the fringe - in the case of groups like the FLDS, "pushes it into isolated, authoritarian, quasi-state cult compounds where [brainwashing and rape] are most likely to take place"? ${ }^{34}$

The Liberal's sense is that the latter mode of determination predominates. That is, in contrast to the reticent Progressive, the Liberal affirms an attitude of 'polygamy optimism' - the hope that, in

as a way of highlighting an important conjecture: namely, that what drives much opposition to the legalization of polygamous unions simply is the fact that people find polygamy to be disgusting or distasteful. This is not to say that such persons evince concerns about harm as a mere fig leaf to rationalize their disgust - their concerns about harm are genuine. But I believe that psychologically, much of the motive for opposing Liberalism does stem from the feeling that polygamy is gross or distasteful. (I take 'unsavory' to have connotations that include not only 'disgusting' or 'distasteful', but also 'harmful' - so for this reason I believe it is a useful word here.) Thus, I retain this label to impress upon the reader the fact that, once one's concerns about polygamy-based harms are significantly diminished (and I hope to have contributed to such diminishment in the following pages), any residual opposition the reader feels quite possibly originates from non-rational disgust, distaste, or fear.

33 Which status is of course partially constituted by the illegality of the unions which play a central role in the common life of such groups.

34 Will Wilkinson, Flybottle blog. April 28, 2008: http://www.willwilkinson.net/flybottle/2008/04/28/down-on-thecompound/ 
normalizing polygamy by according legal recognition to polygamous marriages, we might expect to observe that the unsavory practices now largely characteristic of polygamous societies become decreasingly pervasive. We of course cannot fully defend that conjecture here. But we can observe that the history of the gay rights movement may provide some license for the Liberal's optimism respecting polygamy in this regard. For consider that, at one time in the recent past, it may have been much more natural to conclude that a homosexual orientation was 'deviant' and 'depraved' and thus unworthy of the sorts of legal recognition and stature attendant to the institution of marriage - due to a parallel observation about the 'unsavory' nature of homosexuality. The relative naturalness of this judgment was the result of the debauchery widely - and not wholly unjustly thought to characterize the gay lifestyle. That the analogous, anti-Progressive version of the 'Objection from Unsavoriness' might have held more force a generation or more ago, is a fact acknowledged even by many Progressive advocates. As Rauch allows, the behavior typified by the "bathhouses and wanton sex of gay San Francisco or New York in the 1970s" was "tragic"; he likens it to that of "wildings in Central Park, gangs in Los Angeles, football hooligans in Britain, skinheads in Germany, fraternity hazings in universities, grope lines in the military," and other "marauding or orgiastic packs" of young males. ${ }^{35}$ It is at least comprehensible, then, that Traditionalists of that era pointed to unsavory features of the gay culture of the times - much as current anti-Liberals appeal to certain unsavory features widely characteristic of polygamous cultures today - as a reason to resist the liberalization of marriage policy.

Presently, though, this judgment regarding the generally debauched nature of the gay lifestyle is not nearly so widespread. Instead, it is largely recognized that homosexuals differ from heterosexuals only with respect to sexual orientation, and not in the more comprehensive, 'wholly-foreign-lifestyle'

\footnotetext{
${ }^{35}$ Rauch [op. cit., 263].
} 
sort of manner that was once more widely believed. What has changed? It has become something of a commonplace to remark that this cultural shift was effected - not in the pages of philosophy journals, the opinion pages of newspapers, nor even along the routes of Gay Pride parades - but rather, in the arena of popular culture. Hollywood won this battle in the 'culture war', it is said. While true, and largely informative, this observation should not obscure the fact that part of the reason Hollywood has been successful in portraying the gay and lesbian community as 'comfortably mainstream', is that the community, as a whole, has taken steps to ensure that this portrayal is largely accurate. Thus we have observed an important dialectic unfold: a group is legally marginalized, and it exhibits some 'fringe' characteristics; these characteristics condemn it to further marginalization in the eyes of the mainstream majority. Somehow, this mutually-reinforcing cycle of self- and otherimposed marginalization gets broken, and the result is that the marginalized group is no longer as marginalized by the mainstream. The group itself to some degree casts off its former 'fringe-y' traits, which results in further mainstream acceptance and decreased marginalization, which leads to ... and so forth. ${ }^{36}$

The existence of this dialectic seemingly reveals that none of the 'fringe-making' features of the homosexual orientation - none of its accompanying characteristics which led many observers of past generations to dismiss it as deviant and depraved - are intrinsic to homosexuality itself. They were, as many now recognize, only contingently related to the homosexual orientation. The history

\footnotetext{
${ }^{36}$ In noting this parallel between the recent history of the gay-rights movement and the (potential) future trajectory of polygamous communities, we must also note an important asymmetry between the two cases: that, whatever 'fringe-y' traits the gay community may have once embodied, membership in this community, and participation in its practices, was a consensual matter. Whereas many of the most troubling aspects of contemporary polygamous practice involve the harms that befall the non-consenting members of polygamous unions: children. For bringing my attention to this point, I am grateful to an anonymous reviewer for Social Theory and Practice. While I cannot pursue this issue fully here, I would refer the interested reader to Jeremy Garrett's discussion at his [2009: 164ff.], where he argues convincingly that such (wholly legitimate) concerns about child welfare are better addressed via legal arrangements that protect children directly, through legal categories such as parent and guardian, rather than relying on marriage policy as a sort of proxy for the more direct protection of child welfare.
} 
of the past several decades further suggests that the marginalization and perceived 'unsavoriness' of homosexuality was, to a considerable degree, a result of its being 'illegal'37 - and of lifelong monogamous homosexual partners having no means of securing legal recognition for their partnerships - rather than being the cause or source of its illegality. The lesson here is that the same story may be accurate with respect to polygamy. We may be on shaky ground appealing to the unsavory character of polygamous societies as a reason for keeping polygamous marriage illegal, as this very illegality may in fact be a significant factor contributing to the prevailing patterns of, e.g., inequality and oppression in polygamous societies. ${ }^{38}$

But the reticent Progressive can avoid these arguments for Liberal optimism regarding the likely salubrious effects of legalizing polygamous marriage, by abjuring appeal to empirical considerations and forecasts altogether. For there is an important objection to the effect that, its connections (contingent or otherwise) to unseemly practices like exploitation, child marriage and rape notwithstanding, polygamous unions suffer from the intrinsic normative defect that they are inherently inegalitarian. If this is correct, then the Progressive has identified principled limits to the scope of the Liberal's polygamy optimism. For, while the normalization of polygamous marriage

\footnotetext{
${ }^{37}$ Strictly speaking, of course, homosexuality wasn't illegal - but many homosexual acts were criminalized.

${ }^{38}$ We should note the possibility that this favorable comparison with the history of the gay-rights movement will not necessarily strike every Progressive as unwelcome. Whether or not it does will depend largely on how prepared that Progressive is to admit that she might have opposed SSM in the 1970's, or that she might support polygamous marriage in the 2030's. Some Progressives may take pause at the suggestion that - were they to have come of age in a previous generation, or were they to have come of age a generation hence - their stance vis-à-vis the proper scope of civil marriage would depart dramatically from their current one. Such Progressives may want to reconsider their current position, and contemplate whether either the Traditionalist or the Liberal position now seems more attractive, upon further reflection. Other Progressives, on the other hand, may be more comfortable with the notion that their stance with respect to civil marriage is temporally- or generationally- contingent. They may reason as follows: "Gay and lesbian romantic behavior had a largely unsavory character a generation ago, and that was grounds then for opposing the extension of marriage so as to include same-sex couples. Gay sexual behavior does not now exhibit these same pervasive unsavory features; thus there are no present grounds for opposing the extension of marriage so as to include unisex couples. Likewise: polygamous communities, such as the FLDS, currently exhibit pervasive patterns of exploitation and sexism, and that provides a reason to oppose extending marriage so as to include polygamous unions. But at some future date, polygamous unions may generally cease to exhibit these unsavory features, and there will no longer be grounds to oppose the legalization of polygamous marriages." For such a Progressive, the 'unwelcome comparison' objection I have just articulated is not decisive, because the comparison is simply not that unwelcome.
} 
may decouple the linkage between it and certain unfortunate behavioral patterns already mentioned, it will not be able to surmount certain structural features of these unions - features which by their very nature are inegalitarian and sexist. For instance, Thom Brooks cites the "asymmetrical ability to divorce" as one such example of structural inequalities inherent in the nature of polygamous unions. To illustrate this asymmetrical power, Brooks asks us to imagine a man who has three wives: "While each wife may have consented to each person entering into her marriage, the wives may only consent to agreeing that another woman enter the marriage: no wife may divorce any other wife. Each wife may only either agree to all fellow polygamous partners, or divorce her husband and leave all partners." 39 The husband, however, has more latitude in this regard: he enjoys the (unilateral) privilege of expelling selected wives from the marriage arrangement.

How strong is this 'essentialist' Progressive argument? Before giving it a full examination, we should first observe that, in many of its manifestations, this argument is actually directed only at polygyny. Typically, the asymmetrical power relations that frequently obtain between the (single) husband and his (multiple) wives are cited as problematically sexist. Further, this gender asymmetry is frequently seen as exacerbating antecedent cultural inequalities. In this way, extant polygynous practices are faulted insofar as they are dependent upon, and further productive of, deep structural sexual inequalities that already prevail in the polygyny-condoing culture. (Analogous arguments could, I suppose, be made about the inequities inherent in polyandry - although it will not often be the case that appeal to an antecedent structural cultural bias against men will carry much plausibility. In the literature, extant polyandrous practices are more typically regarded as the understandable, if not wholly commendable, result of conditions of extreme scarcity, such as those that obtain in rural

\footnotetext{
${ }^{39}$ Brooks [op. cit., 13].
} 
regions of Bhutan, Mongolia and Tibet, where polyandry is sometimes practiced. ${ }^{40}$ ) But this polygyny-centered argument will not have universal applicability to the issues raised by polygamy more generally. Obviously, issues of gender asymmetry do not arise for all cases of polygamy - they will not arise, for instance, in circumstances where there is an equal number of husbands and wives, or where all members of the marriage are of the same gender. Furthermore, it is certainly possible that all parties to an unequally-gendered polygamous marriage could be fully sensitive to the possibility that their union could give rise to a gender imbalance, in favor of either gender. It is also possible that these parties all fully recognize that antecedent cultural sexual inequalities might covertly manifest themselves, thereby tipping the balance of power in the marriage - even in one that is equally-gendered - in favor of the members of one sex or the other. In these types of situations, the parties to such marriages could take extra care to craft their unions so as to prevent their succumbing to such inegalitarian gender imbalances, or exploitive practices.

To his credit, Brooks tries to avoid the mistake involved in conflating polygyny and polygamy and then citing the inequities that can easily arise in the former practice as grounds for dismissing the latter tout court. For example, in elaborating his worry regarding the asymmetrical power of divorce supposedly inherent in polygamous unions, Brooks acknowledges that this asymmetry arises regardless of "whether a polygamous marriage is polygynous or polyandrous." ${ }_{41}$ But even here, his argument is insufficiently general, for it fails to apply to polygamous unions of the 'group marriage' variety, wherein there are multiple members of each gender: Brooks simply stipulates that polygamy entails "either one man or one woman, with multiple partners of the opposite sex." 42 Similarly, his concern that polygamy "discriminates on the basis of sexual orientation in excluding non-

\footnotetext{
40 See Brooks [op. cit., 1].

${ }^{41}$ Brooks [op. cit., 13].

42 Brooks [op. cit., 13-14].
} 
heterosexuals" ${ }^{\prime 3}$ is predicated on an unduly narrow conception of polygamous unions. Indeed, the only argument Brooks offers that might not be applicable to only this or that proper subset of polygamous unions comes during his discussion of 'polyamory' (the term he uses to refer to group marriage) - a practice that holds out the promise of "greater inclusiveness, permitting both heterosexuals and non-heterosexuals opportunities to form relationships with multiple partners." ${ }^{44}$ And here, the only objection Brooks can muster is one that has nothing to do with any alleged intrinsically inegalitarian feature of polyamorous unions. Instead, we are told only that we should be reluctant to embrace polyamorous ${ }^{45}$ unions for the same reason Brooks told us earlier we should be hesitant to accept polygamous ${ }^{46}$ unions: that the acceptance of polyamory/polygamy in theory is apt to lead to the prevalence of (only) polygyny (together with all its attendant inegalitarian tendencies) in fact: "However, the primary problem with polyamory is not unlike what we have seen with polygamy. Virtually all polygamous marriages are polygynous in fact. There is no evidence that polyamorous relationships are less likely to lead to polygyny similarly." 47

Once we have eliminated from consideration all forms of it which apply only to an unsuitably restricted sub-set of polygamous arrangements, what remains of the argument that polygamous unions are necessarily and inherently (as opposed to contingently and historically) inegalitarian, or prone to exhibit exploitive and illiberal tendencies? I am unaware of any argument which succeeds in isolating intrinsically inegalitarian features of any possible form of polygamous union - I am aware only of arguments which, like those of Brooks canvassed above, fasten on some feature of, e.g., polygnous unions. And indeed, this is what we should expect. For, given the diverse and varied

\footnotetext{
43 Brooks [op. cit., 14].

44 Brooks [op. cit., 15].

${ }^{45}$ In his (not our) stipulative sense of the term - one that is, roughly, coextensive with 'group marriage'.

${ }^{46}$ In his (not our) stipulative sense of the term - one that includes polygynous and polyandrous unions, but not groupmarriage or polyamorous arrangements.

${ }^{47}$ Brooks [op. cit., 15].
} 
forms of polygamous life-partnership countenanced by a Liberal regime of marriage policy, it would be quite surprising if there were an 'essentialist' argument that succeeded in generalizing over any such partnership. As predicated of life-partnerships, polygamous is a disjunctive kind - insufficiently projectible to support the sorts of universal generalizations that reticent Progressives like Brooks wish to offer.

To summarize: the Progressive may seek a principled ground for resisting the apparently Liberal character of her arguments for SSM by citing the unsavory nature that much polygamous practice has assumed, and continues to assume. She then concludes that such an unsavory practice is undeserving of the sorts of official recognition and promotion as would be afforded by the legal recognition of polygamous unions. The Liberal might retort that the observed association (admittedly well-grounded empirically) between polygamy and, e.g., sexism, exploitation, child marriage and rape, obtains only as a contingent matter. In support of this assertion, the Liberal might cite favorable parallels with the gay-rights movement: the history of homosexual emancipation is one in which similar worries concerning the 'unsavory nature' of non-majority sexual practices proved to be based upon contingent features of the practice (and likely the effect, rather than the cause, of their previous marginalization), not intrinsic ones. In response, the Progressive might offer an argument that some or all of the objectionable features of past and present polygamous practice inhere in polygamy itself - though as we have just observed, such an argument would be difficult to make out, and seemingly no Progressive has done so yet.

Even if such an argument could be made out, however, there is one final objection the Liberal might deploy in response to the Progressive invocation of the Objection from Unsavoriness - one that will be familiar to anyone conversant with feminist political thought. This objection consists of the 
simple observation that the traditional heterosexual family, no less than the polygamous (or at least the polygynous) family, has been a repository for unjust, inegalitarian, sexist, exploitive practices for well nigh its entire history. If the stain of historically prevalent injustice is sufficient to rule polygamous marriage out of court, it ought likewise to rule even traditional marriage out of court. This argument - a form of the previously-encountered BYCBS - pushes the Progressive, not on ahead to the Liberal position, nor even back towards the Traditionalist stance, but rather towards the outright abolition of marriage.

Of course, the Progressive has resources here that can block the retreat to abolitionism. For she can respond by acknowledging the oft-exploitive character that marriage has traditionally assumed, but then asking what follows from this acknowledgement. Was the proper response to this problem really the abolition of marriage? Or was it rather to seek to redress the injustices that often characterized married unions, and to seek to undermine the cultural norms and patterns of expectations that contributed to marriage's status as a de facto site of injustice? Was not the fitting response to offer up alternative visions of more just, more egalitarian, more humane versions of marriage, conceived as an equal partnership?

But if the Progressive avails herself of this move to resist the pressure towards abolitionism, she has admitted a Liberal Trojan horse through the gates. For does not the same reasoning hold with respect to the current state of polygamous unions? Should we not likewise seek to 'bring these marriages into the fold', to humanize and soften and modernize the institution of polygamous marriage, rather than condemn these unions to remain marginalized? Why should we abandon polygamous unions to a fate not shared by heterosexual couplings; why should they alone remain repositories of injustice? Why not seek to ensure that persons attracted to this lifestyle might access 
it with a greater chance of finding fulfillment, and with less peril that they will succumb to the traditions and customs of exploitation that (unfortunately) currently frequently accompany the practice? After all, these traditions and customs of exploitation, as we noted, are likely not endemic to the institution. ${ }^{48}$

But the specter of abolitionism, just sighted, need not scare the Progressive down this path. Indeed, it need not raise any cause for alarm at all. For our reticent Progressive - as yet unwilling to embrace Liberalism, and yet (thanks to our assistance in Section 2) cognizant of her inability to dig in her theoretical heels anywhere shy of Liberalism - will actually find her strongest ally in the abolitionist - specifically, in the person of the Libertarian, who argues - not for its abolition, quite but rather for the 'disestablishment' of marriage.

\section{Libertarianism}

Recall that we began by addressing our argument to Progressives. We might imagine that many Progressives have left the fold after considering our arguments thus far. Aware (thanks to the considerations put forth in Section 1) that the arguments they formerly invoked to defend Progressivism actually yield Liberal conclusions, and furthermore aware (thanks to our arguments in Section 2) of the difficulties in formulating countervailing considerations for resisting the slide to Liberalism, they now fall squarely in the Liberal camp. But not all Progressives may have been thus converted. Call these the 'squeamish Progressives', in recognition of the discomfort they no doubt feel as a result of their inability to cite principled grounds for their intuitive opposition to legalizing polygamous marriage.

${ }^{48}$ Calhoun [op. cit., 1040-41] also offers a version of this argument. 
Take our squeamish Progressive. How might things stand with her now? Insofar as she remains resolute in her Progressivism - that is, insofar as she remains opposed to legalizing polygamous unions, even as she firmly supports the right of same-sex couples to marry - she must realize that this conviction is not, after all, motivated by her acceptance of abstract philosophical considerations, such as those represented by the Equal Rights and BYCBS arguments. Perhaps she recognizes that her Progressivism flows from her brute revulsion to the very idea of polygamy. Perhaps, more charitably, she has come to recast her Progressivism: she no longer regards herself as espousing a universalistic ethic which, in contrast to the narrow parochialism of her Traditionalist opponent, is open to all comers. Perhaps she has cast off the notion that she is the sort of person who wishes to recognize, legitimate, and celebrate the full flowering of human love and intimate union, in all its diverse and myriad forms. She has come to see instead that, like the Traditionalist she once condemned as narrow and closed-minded, she herself also professes a particular 'thick' conception of marriage (perhaps itself a component module of a more comprehensive conception of the Good Life) - a conception of marriage which, though it is more permissive, embracing, and inclusive than that of the Traditionalist, nevertheless remains a particular and non-universal vision. She is not quite the universalistic 'Liberal'49 she once thought she was.

Likewise, our Progressive has perhaps come to re-conceptualize her political advocacy. No longer can she naively regard her SSM advocacy as having been carried out in the cause of equal liberty or universal equality; no longer can she think the reform she'd been pressing for represents the simple application of the principle of equal opportunity before the law. Insofar as her Progressive policy proposals conferred benefits and rights upon gays and lesbians, but did not extend these same rights

\footnotetext{
49 In the broadest sense of the term, not in the narrow stipulated sense in which it has been used in this paper to
} demarcate a particular position on the SSM debate. 
and benefits to would-be polygamists - and insofar as she is unable to find principled grounds for the exclusion of these would-be polygamists - she is unable to regard her prior politicking as being universalistic in character. Unable to regard her prior Progressive politicking as being universalistic in character, she is no longer able to assimilate it to the project of striving to bring existing liberal legal practice in line with liberal theory and aspiration. Resigned to the illiberal character of her prior advocacy, she now regards the Progressive cause as simply an exercise in identity politics, or specialinterest lobbying.

Now suppose that, upon reflecting on her new-and-improved self-fathoming, our squeamish Progressive is dissatisfied. She is not dissatisfied thinking that her moral outlook, described in the second paragraph of this section, is not the 'Liberal' one she once thought it was. "So I'm no (capital-L) Liberal," she may think. "I've got my own controvertible notion of life's meaning and value, my own account of human flourishing. And it's not as inclusive in character as those of my more truly Liberal friends. But that's OK: one of the merits of a pluralist liberal democracy is that it can tolerate and accommodate a wide array of such notions of the Good - even those notions, like mine and the Traditionalists', that are less-than-fully inclusive ... even some that are quite parochial and provincial." Her dissatisfaction results, rather, from her re-constituted understanding of her political orientation, described in the third paragraph of this section. Specifically, she is dismayed to find that she no longer affirms a liberal political outlook.

Is there hope for our squeamish Progressive? Can she (coherently) profess a liberal politics, compatibly with her Illiberal moral outlook? Fortunately, she can. For the policy recommendations of the Libertarian provide the resources for espousing a thorough-going liberal outlook in politics, 
even as they sit comfortably with less-than-fully-Liberal moral views - such as those endorsed by our recovering Progressive.

The Libertarian position, of course, recommends the complete 'dis-establishment' of marriage - it holds that the state has no reason in the first place to be in the business of certifying particular types of contractual unions, and according them privileged moral or legal status. ${ }^{50}$ So as a matter of private morality, our Progressive-turned-Libertarian may continue to affirm that essentially, marriage is an institution that ought to be reserved for couples - of whatever gender. As a matter of public policy, though, she is willing to concede that it isn't the state's place to identify privileged forms of life-partnership. From the state's perspective, contracts for life-partnership are matters for individuals, couples, and $n$-tuples to work out on their own. The liberal right to freedom of

\footnotetext{
${ }^{50}$ I presume the main contours of a Libertarian marriage policy to be broadly familiar, so I will not outline them in any more detail here. But for readers who wish to further assess the plausibility and practicability of such a regime, I make three suggestions. (1) The first is to refer the reader to the growing body of literature on the 'privatization' of marriage for example, Boaz, David: "Privatize Marriage: A Simple Solution to the Gay-Marriage Debate." Slate: April 25, 1997. Available at http://www.slate.com/id/2440/; Metz, Tamara: "The Liberal Case for Disestablishing Marriage." Contemporary Political Theory 6 [2007]: 196-217; West, Robin: Marriage, Sexuality and Gender. Boulder, CO: Paradigm Publishers, 2007; Torcello, Lawrence: "Is the State Endorsement of Any Marriage Justifiable? Same-sex Marriage, Civil Unions, and the Marriage Privatization Model.” Public Affairs Quarterly 22(1) [2008]: 43-61; Garrett, Jeremy R. "Marriage Unhitched From the State: A Defense." Public Affairs Quarterly 23(2) [2009]: 161-180; Brake, Elizabeth: "Minimal Marriage: What Political Liberalism Implies for Marriage Law." Ethics 120 [2010]: 302-37; and Sunstein, Cass, and Richard Thaler: "Privatizing Marriage." The Monist 91(3 \& 4) [2008]: 377-387. The latter is particularly instructive, especially its opening description of a 'science fiction' world of thoroughly-privatized marriage (though theirs is a vision wherein marriage remains a 'couples-only' affair). A brief and helpful overview of this literature can be found at http://en.wikipedia.org/wiki/Marriage privatization. (2) For an example of real-world legislation that implements many aspects of a Libertarian scheme of privatized marriage, I direct the reader's attention to the recent passage of Colorado's 'Designated Beneficiary Law': see, e.g., http://www.designatedbeneficiaries.org/. (3) Regarding the practicability of such an arrangement, it might be instructive to consider that we currently manage our practices of bequest and inheritance without the aid of official state licenses and statuses, and to no apparent ill effect. When one decides to create a will, one simply consults an attorney and draws one up. Could not a similar system work, then, for life-partnership arrangements? In such a system, whenever a couple or $n$-tuple wanted to establish such an arrangement, they would simply seek legal counsel and draft a contract suitable to their purposes. (Imagine a different 'science fiction' world, one in which the government regulates and sanctifies wills in much the same manner that it now regulates and certifies marriages. Can we not easily imagine such an arrangement giving rise to a set of debates paralleling current controversies over marriage policy? For example, suppose the Official State Format for wills required that some portion of one's property be passed to one's children. Imagine, then, a controversy to arise regarding the proper definition of 'children': does this mean only biological offspring? do adopted children count? etc. No doubt a concerted effort would be made by the Step-Child Rights movement to amend federal bequest policy so as to extend beneficiary rights to their constituents, and so forth. It's worth noting that we've never experienced these controversies because the institution of inberitance has always been adequately 'privatized'.)
} 
association, then, guarantees our newly-minted Libertarian the right to identify with whatever private marriage-performing institution she prefers - no doubt she will affiliate with one (be it a church, a synagogue, a mosque, or something else entirely) that is inclusive enough to sanction same-sex unions, yet exclusive enough to demure at the prospect of legitimizing polygamous unions. ${ }^{51}$

Ultimately, I would argue - not only that the Libertarian position presents an attractive option for our squeamish-about-polygamy Progressive - but that it is the most attractive position to (almost) everyone. So a full defense of the Libertarian position with respect to civil marriage would have to address the Liberal and the Traditionalist as well. I cannot offer this full defense here, but in closing I shall say just a bit to motivate the thought that this Libertarian position is a broadly attractive view. To do that I will seek to establish a close connection between the Libertarian position and a separate ideal, which has considerable independent plausibility: the ideal of liberal neutrality.

The force of the Libertarian position might best be observed by casting it in terms of the state's duty to aspire to some sense of neutrality with respect to its (reasonable) citizens' competing conceptions of life's meaning and value. How ought a 'neutral' state respond to the controversy posed by samesex marriage? As our previous discussion suggests, three options immediately present themselves: it can maintain the institution of civil marriage in its present form (thereby pleasing the Traditionalists, while offending same-sex couples and polygamists); it can expand the institution's scope so as to include same-sex marriage (thereby offending the Traditionalists, while still managing to exclude polygamists); or it can more radically expand the institution so as to include polygamous unions as

\footnotetext{
51 It lies beyond the scope of this paper to address the 'transition problem' - i.e., the question as to how the state might dis-establish an already-established institution such as marriage. But I refer interested readers to the final chapter of West [op. cit.] as perhaps the most fully developed discussion of how such a transition might be effected. In West's case, the transition under consideration is one in which the (more inclusive) institution of civil union comes to supplant the current (restrictive) institution of marriage; nevertheless, her discussion is stimulating and instructive for thinking about the present case as well.
} 
well (thereby pleasing the Liberals while infuriating the Traditionalists - and likely alienating a fair number of Progressives besides). It seems that whichever of these courses it sets itself, the state is bound to act non-neutrally - it seemingly cannot avoid running afoul of the cherished values of some of its citizens.

But of course, it's the option that does not immediately present itself - the Libertarian option - that allows the state to maintain some reasonable semblance of neutrality. For by refusing to privilege any contractual unions for life-partnership with an honorific status (and all the legal privileges pertaining thereunto), the state does act neutrally with respect to competing moralized conceptions of marriage. Such 'official state agnosticism' with respect to the proper scope of marriage may not please a lot of people, but at the same time no citizens will find themselves disadvantaged by the state's pursuit of policies that rest on thick, robust, and controvertible conceptions of the Good (or, at least, of the Good Marriage) - conceptions such citizens may not share. ${ }^{52}$

The question as to whether states ought (or even can) aspire to neutrality vis-à-vis their citizens' diverse and conflicting conceptions of the Good Life is itself a matter of some controversy, of course. Perfectionists, for instance, will demur at my suggestion that states should even worry about aspiring to this kind of neutrality. But I hope to have shown that, to the extent that 'neutralist' considerations get any grip on us at all, they incline us strongly towards a Libertarian solution to the issue posed by SSM, rather than to a Liberal, Progressive, or Traditionalist stance. At the very least,

\footnotetext{
52 Torcello [op. cit.] advances a similar argument, though cast more in the language of Rawlsian public reason than in the language of liberal neutrality. He is largely silent on the place of polygamous unions in his 'Marriage Privatization Model' (as he calls it), though he admits the possibility (p. 54) that public reasons could be advanced in favor of extending the institution of civil unions so as to include polygamous partnerships.
} 
I have shown that the Libertarian stance offers a plausible and defensible alternative to a Progressive not inclined to progress to Liberalism..$^{53}$

\footnotetext{
${ }^{53}$ I am grateful to audiences at Bowling Green State University and the University of Maryland, and to two anonymous
} reviewers for Social Theory and Practice, for helpful comments on earlier versions of this paper. 